\title{
Evaluation of Role of Minimally Invasive Sinus Technique (MIST) in patients of Chronic Rhinosinusitis
}

\author{
Authors \\ Naveen Agrawal $^{{ }^{*}}$, H.S. Sharma ${ }^{2}$, Pulkit Khandelwal ${ }^{3}$, Varsha Raghuvanshi ${ }^{4}$, \\ Mohit Samadhiya ${ }^{5}$, Anand Sharma ${ }^{6}$ \\ ${ }^{1}$ Associate Professor, ${ }^{2}$ Professor, ${ }^{3-6}$ Postgraduates \\ Department of Otorhinolaryngology (ENT), IMCHRC, Indore MP INDIA \\ *Corresponding Author \\ Naveen Agrawal \\ Email: navinagrawal12@gmail.com
}

\begin{abstract}
Background: MIST is stepwise intranasal intervention with defined beginning and end for all patients regardless of disease severity, there by standardizing the procedure for surgeons and patients alike. In the present study the role of minimal invasive sinus technique is evaluated in terms of both a surgical modality of choice and patients satisfaction. This study is done to assess the indications, techniques, results of MIST, And to assess the efficacy and reliability of MIST.

Material and Method: This prospective study is conducted in the department of otorhinolaryngology, Index Medical College Hospital and Research Centre, Indore from Sep 2014 to Sep 2016. A total of 60 patients (age ranged from 9 years to 50 years) having nasal and sinus complaints were selected. Detailed Clinical evaluation, preoperative diagnostic nasal endoscopy, CT Para-nasal sinus was done and MIST was performed in all cases. Post-operative subjective improvement was assessed.

Result: The main symptoms in the study group was nasal obstruction followed by nasal discharge. On anterior rhinoscopic examination DNS was seen followed by ITH. Pre-operative nasal endoscopy showed MPD in OMC followed by MPD in ET, polyp was also seen in cases. The most striking anatomical variants seen after pre-operative nasal endoscopy was swollen agger nasi cells followed by Overpnuematized bulla, medially bent U.P, laterally bent U.P, polyploid U.P and paradoxically bent M.T. these findings were confirmed on CT PNS. Various surgical procedures were performed including uncinectomy followed by $C B$ exteriorization, opening of bulla, anterior ethmoidectomy, posterior ethmoidectomy and sphenoidectomy. Post-operative subjective improvement was assessed in every patient. No major post-operative complication occurred in this study.

Conclusion: Our study shows that MIST is a safe and effective method of treatment in cases of Chronic Rhino-sinusitis in all age group of patients, by providing better understanding of sinus pathophysiology and opens the new horizons of treating them with minimal injury to the surrounding normal mucosa.

Keywords: MIST, CHRONIC RHINOSINUSITIS, FESS.
\end{abstract}

\section{Introduction}

The aim of any surgery is to inflict minimal trauma to the surrounding tissues resulting in less swelling; less edema, less pain and less morbidity with optimal successful results from the patient's point of view both anatomically and physiologi- 
cally. Nasal symptoms are among the commonest reasons for which a patient seeks Rhinologist's advice. More so the management of these symptoms forms a significant part of workload of Rhinologist's. With rapid advancement and increased availability of newer technology, surgical interventional techniques are getting refined and perfected.

Originally, proponents of FESS emphasized that it provides a conservative and effective surgical intervention, rarely requiring a middle meatal antrostomy or stripping of diseased nasal mucosa. Over time however, there has been a departure from these conservative principles, with tendencies towards more aggressive intervention. Minimally Invasive Sinus Technique (MIST) is true embodiment of Messerklinger's functional concept and an improvement in FESS by providing an anatomical based, reproducible approach to sinus surgery.

MIST is based on exact identification of focal disturbances, refined surgical interventions and functional restoration of aeration and drainage of various sinuses by Muco-cilliary clearance.

MIST is much more than not performing a middle meatal antrostomy. The procedure is only step wise intranasal intervention with defined beginning and end for all patients regardless of disease severity, there by standardizing the procedure for surgeons and patients alike. It is important to state that minimally invasive technique is not minimal surgery, but the invasion into the nose and sinus is minimal. This also enables the surgeon to preserve important surgical landmarks to avoid serious intraorbital and intracranial complications, which can occur during endoscopic sinus surgery. It is an attractive alternative to traditional headlight approaches to nasal surgery.

In the present study the role of minimal invasive sinus technique is evaluated in terms of both a surgical modality of choice and patients satisfaction.

\section{Material and Method}

This prospective study is conducted in the department of otorhinolaryngology, Index Medical College Hospital and Research Centre, Indore from Sep 2014 to Sep 2016.

A total of 60 patients (age ranged from 9 years to 50 years) having nasal and sinus complaints were selected. The patients were considered to have rhinosinusitis when they had nasal congestion, nasal obstruction, rhinorrhea, headache etc. The patients having these symptoms and sign for more than one month and all those who were treated conservatively for one month prior to this study were selected. Detailed Clinical evaluation, preoperative diagnostic nasal endoscopy, CT Para-nasal sinus was done and MIST was performed in all cases. Post-operative subjective improvement was assessed.

\section{Different Surgical Rpocedures For Isolated Pathologies}

The different surgical procedures performed such as :-

1. Correction of high deviated nasal septum with removal of spur

2. Middle turbinate - concha bullosa \& paradoxical turbinate

3. Uncinate process and maxillary ostium reconstruction at physiological site.

4. Bulla ethmoidalis

5. Frontal recess

6. Posterior ethmoids

7. Sphenoid sinus

We have assessed the post-operative subjective improvement of patients undergoing MIST by asking questions regarding subjective improvement of their symptoms in post-operative followup period.

After assessing the individual response (postoperatively) regarding their symptomatology and improvement in it, patients were divided into three categories.

Category-I- Patients with complete satisfaction after surgery regarding their symptoms.

Category-II- Patients with general satisfaction post operatively. 
Category-III- Patients with no improvement.

\section{Result}

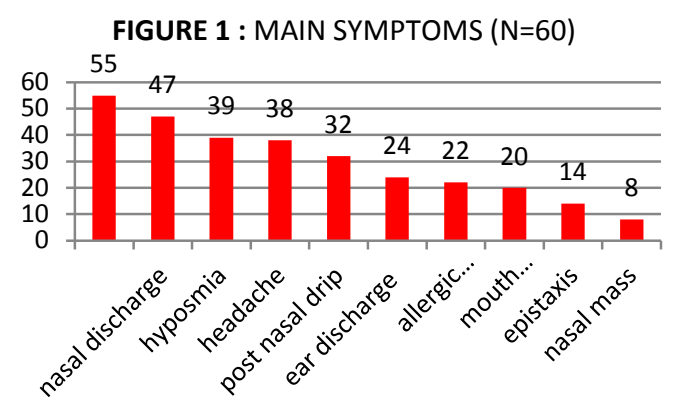

The main symptom in the group of patients (figure 1 and table 1) was nasal obstruction seen in 55 (91.66\%) cases. Out of which 12 cases had continuous, 43 recurrent, 45 bilateral and 10 unilateral nasal obstruction. Nasal discharge was seen in 47 (78.33\%) cases which was watery in 08 cases, mucoid in 19 cases and mucopurulent in 11 cases. Hyposmia in $39(65 \%)$ cases, headache in $38(63.3 \%)$ cases, PND in 32(53.3\%) cases, ear discharge in 24(40\%) cases, allergic symptoms in $22(36.6 \%)$ cases, mouth breathing in $20(33.3 \%)$ cases, epistaxis in $14(23.3 \%)$ cases and nasal mass in $08(13.3 \%)$ of cases.

\begin{tabular}{|c|c|c|}
\hline \multicolumn{3}{|c|}{$\begin{array}{l}\text { Table 1:-Main Symptoms During Clinical } \\
\text { Examination }(\mathrm{N}=60)\end{array}$} \\
\hline SYMPTOMS & NO. OF CASES & $\%$ \\
\hline Nasal obstruction & 55 & 91.66 \\
\hline Nasal discharge & 47 & 78.33 \\
\hline Hyposmia & 39 & 65 \\
\hline Epistaxis & 14 & 23.3 \\
\hline Headache & 38 & 63.3 \\
\hline Mouth breathing & 20 & 33.3 \\
\hline Nasal mass & 08 & 13.3 \\
\hline Post nasal drip & 32 & 53.3 \\
\hline Allergic symptoms & 22 & 36.6 \\
\hline Ear discharge & 24 & 40 \\
\hline
\end{tabular}

On anterior rhinoscopic examination the most obvious finding was DNS in $56(93.33 \%)$ patients, inferior turbinate hypertrophy (ITH) was noted $26(43.33 \%)$ cases out of which $15(25 \%)$ were unilateral and 11(18.33\%) were bilateral. Middle turbinate hypertrophy (MTH) was seen in total of $29(48.33 \%)$ of cases out of which $22(36.67 \%)$ were unilateral and $7(11.67 \%)$ were bilateral. Polyp was noted in 22(36.67\%) cases out of which
$6(10 \%)$ cases were unilateral and $18(30 \%)$ cases were bilateral. Mucopurulent discharge was seen in total of $11(18.33 \%$ ) cases of which $5(8.33 \%)$ were unilateral and 6(10\%) cases bilateral. Sinus tenderness was elicited and came to be positive in 26(43.33\%) cases.

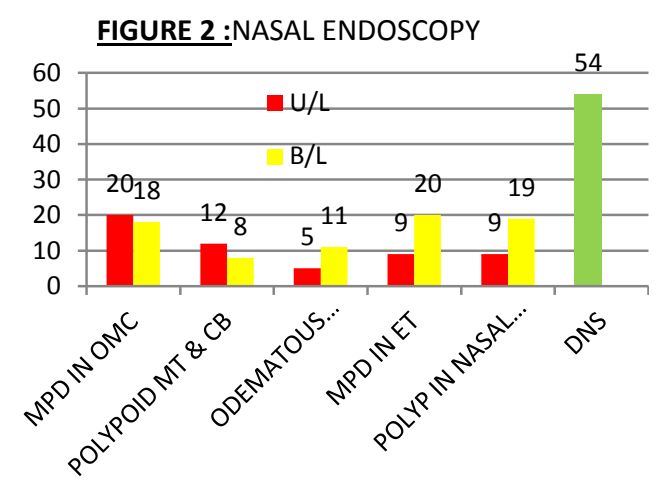

Pre-operative nasal endoscopic evaluation showed various pathological abnormalities (figure 2). DNS was seen in 54(90\%) cases in contrast to anterior rhinoscopic examiantion DNS was found to be in 56 cases. Polypiodal MT or concha bullosa was seen in 20(33.33\%) cases of which $12(20 \%)$ were unilateral and 08(13.33\%) bialateral. MPD in OMC was seen in 38(63.33\%) cases out of which 20(33.33\%) unilateral and $18(30 \%)$ bilateral. MPD in ET was seen in $29(48.33 \%)$ cases of which $09(15 \%)$ were unilateral and 20(33.33) were bilateral. Polyp was noted in nasal cavity in $28(46.67 \%)$ cases of which Ethmoidal polyp was seen in $21(35 \%)$ patients out of which $18(30 \%)$ were bilateral and $3(5 \%)$ had unilateral ethoidal polyp. And 6(10\%) had unilateral antrochoanal polyp. And the most striking finding encountered was nasal cholesteatoma detected in $1(1.67 \%)$ of cases.

FIGURE 3 : ANATOMICAL VARIATIONS ON NASAL ENDCOSCOPY

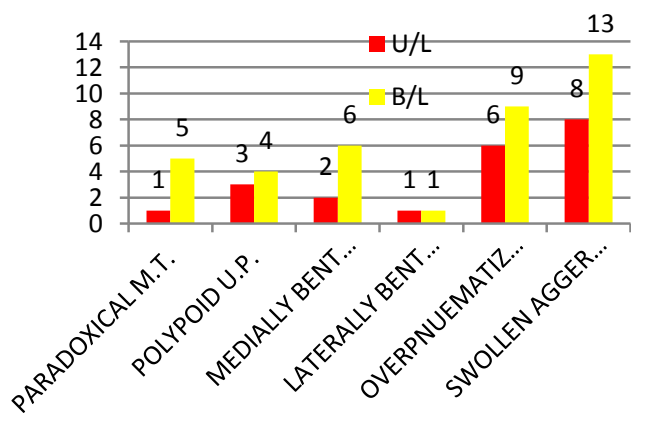


After undergoing Pre-operative nasal endoscopy patients were also found to have some anatomical variants as shown in figure 3. The most striking variant was swollen agger nasi cell in 21(35\%) cases of which $8(13.3 \%)$ cases unilaterally and $13(21.67 \%)$ cases bilaterally. Overpnuematized bulla was seen $15(25 \%)$ cases of which $6(10 \%)$ were unilateral and $9(15 \%)$ bilateral other anatomical variations detected were paradoxically bent middle turbinate $6(10 \%)$ cases, polyploid uncinate process in $7(11.67 \%)$, medially bentuncinate process $8(13.3 \%)$, laterally bent uncinate process $2(3.33 \%)$.

There are different CT patterns of sinonasal pathology

1] Infundibular pattern:-This is the most limited of the obstructive pattern and diagnosed when there is disease limited to maxillary sinus with obstruction visualized with ipsilateral maxillary ostium/infundibulum.

2] Osteomeatal unit pattern (OMU):-it is caused by occlusion of middle meatus by inflammatory involvement of ipsilateral frontal, anterior and middle ethmoid and maxillary sinus which drain into it. This pattern is quite frequent about $25 \%$.

3] Spheno-ethmoidal recess pattern:-Variable involvement of ipsilateral posterior ethmoidal and sphenoid sinuses and occurs when inflammatory posterior nasal pathology lead to obstruction of sinus ostia in spheno-ethmoidal recess.

4] Sinonasal polyposis pattern (SNP):- Here extensive inflammatory condition leading to polyploid mucosa of nose and PNS with characteristic radiological re-appearance. Medical treatment using steroid is main stay of therapy. FESS is reserved for those patient who do not respond to vigorous medical therapy.

5] Sporadic or unclassified pattern:-Sinonasal disease which cannot be categorized into above 4 patterns is included in this group. This includes findings as retention cyst, mucocele, mild mucoperiosteal thickening and post-operative changes after FESS.

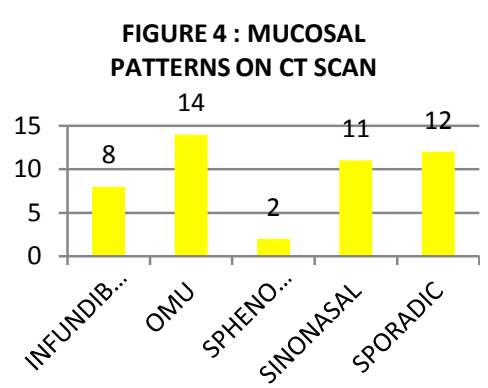

Table 2:-Anatomical Variants Found During Ct Study

\begin{tabular}{|l|l|l|l|l|l|l|}
\hline$\underline{\text { VARIANTS }}$ & $\frac{\underline{\text { TOTAL }}}{\text { NO. }}$ & $\underline{\underline{0}}$ & $\underline{\mathrm{U} / \mathrm{L}}$ & $\underline{\underline{\%}}$ & $\underline{\mathrm{B} / \mathrm{L}}$ & $\underline{\%}$ \\
\hline $\begin{array}{l}\text { MEDIALLY BENT } \\
\text { U.P. }\end{array}$ & 05 & 10.6 & 02 & 4.25 & 03 & 6.38 \\
\hline $\begin{array}{l}\text { LATERALLY BENT } \\
\text { U.P. }\end{array}$ & 01 & 2.1 & - & - & 01 & 2.1 \\
\hline POLYPOID U.P. & 03 & 6.38 & 01 & 2.1 & 02 & 4.25 \\
\hline CONCHA BULLOSA & 19 & 40.4 & 08 & 17.02 & 11 & 23.4 \\
\hline PARADOXICAL MT & 05 & 10.6 & 01 & 2.1 & 04 & 8.51 \\
\hline $\begin{array}{l}\text { OVERPENUMATIZED } \\
\text { BULLA }\end{array}$ & 06 & 12.7 & 02 & 4.25 & 04 & 8.51 \\
\hline HALLER CELLS & 06 & 12.7 & 05 & 10.6 & 01 & 2.1 \\
\hline AGGER NASSI & 39 & 82.9 & 11 & 23.4 & 28 & 59.5 \\
\hline
\end{tabular}

Mucosal patterns shown in our study (figure 4), of which most common being osteomeatal unit pattern seen in $14(29.78 \%)$ cases followed by sporadic pattern seen in $12(25.5 \%)$ cases, sinonasal pattern seen in $11(23 \%)$ cases, infundibular pattern in $8(17.02 \%)$ cases and least being sphenoethmoidal pattern seen in $2(4.25 \%)$ cases.

All the patients were radiologically evaluated after which mucosal abnormality detected on coronal section of C.T. paranasal sinuses. The most frequent involved sinus area was anterior ethmoid region in 60.6\%. mucosal sinus abnormality in maxillary sinus accounted 54\%. Sphenoid sinus was involved in $14 \%$. The diffuse inflammatory mucosal response with turbinate hypertrophy was seen in $10.6 \%$ cases. (Figure 5)

The most commonest of various anatomical variation noted in pre-operative CT study(table 2) was swollen agger nasi seen in 39(82.9\%) cases of which 11(23.4\%) were having unilateral and $28(59.5 \%)$ bilateral, this finding was consistent with nasal endoscopy(figure 3). Concha bullosa was seen in $19(40.4 \%)$ patients of which $8(17.02 \%)$ were unilateral and $11(23.4 \%)$ bilateral. ' 
FIGURE 5 : MUCOSAL ABNORMALITES IN SINUSES ON CT

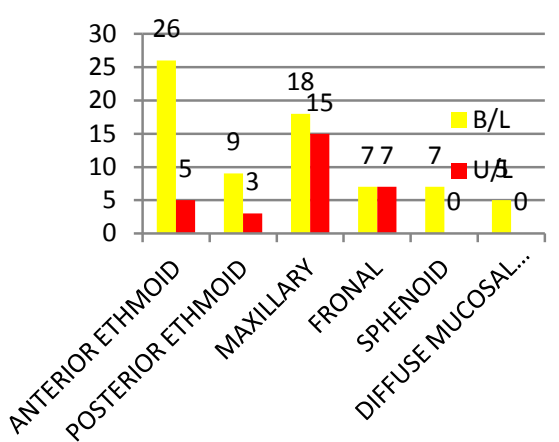

Various other anatomical variations were also noted on pre-operative $\mathrm{CT}$ such as medially bent uncinate process, laterally bent uncinate process, polyploid uncinate, paradoxical middle turbinate and haller cells. After complete pre-operative evaluation MIST was performed. Septoplasty was done in association with MIST In order to get access for nasal endoscope. Various surgical procedures were performed under heading of MIST (figure $6 \&$ table 3).

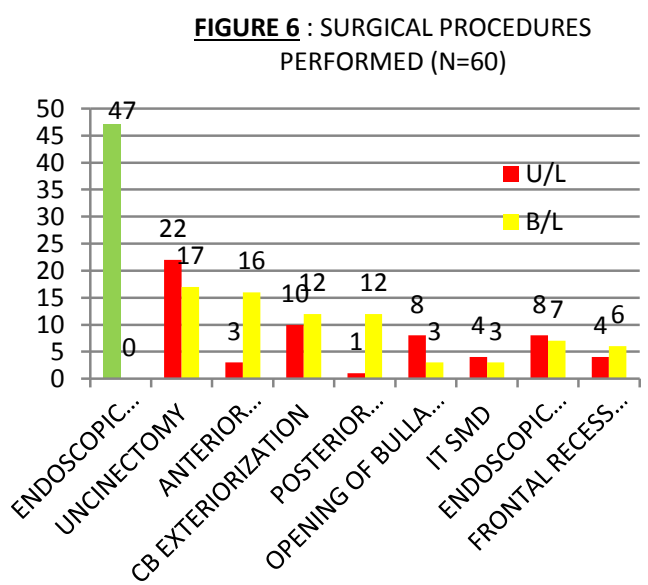

Endoscopic Septoplasty was done in 47(78.33\%) of cases which was in assocaition of MIST to get a wide access for nasal endoscopy. Unicinectomy was done in $22(36.7 \%)$ of cases unilaterally and $17(28.33 \%)$ of cases bilaterally. CB exteriorzation was done in $22(36.7 \%)$ of cases of which $10(16.67 \%)$ were unilateral and

$12(20 \%)$ were bilateral. Opening of bulla ethmoidalis was done in 11 cases of which 08(13.33\%) cases were done unilaterally and 03(5\%) bilaterally. Anterior ethmoidectomy was done in 19 cases of which 3(5\%) went unilateral

\begin{tabular}{|l|c|c|c|c|}
\hline \multicolumn{5}{|l|}{ Table 3:-Surgical Procedures Performed $(\mathrm{N}=60)$} \\
\hline PROCEDURE & $\mathrm{U} / \mathrm{L}$ & $\%$ & $\mathrm{~B} / \mathrm{L}$ & $\%$ \\
\hline Endoscopic septoplasty & 47 & 78.33 & & \\
\hline Anterior ethmoidectomy & 03 & 05 & 16 & 26.7 \\
\hline Uncinectomy ethmoidectomy \& & 22 & 36.7 & 17 & 28.33 \\
\hline CB exteriorization & 10 & 16.67 & 12 & 20 \\
\hline $\begin{array}{l}\text { Posterior } \\
\text { sphenoidectomy }\end{array}$ & 08 & 1.67 & 12 & 20 \\
\hline Opening of bulla ethmoidalis & 04 & 6.67 & 03 & 05 \\
\hline Inferior turbinate submucosal diathermy & 08 & 13.33 & 07 & 11.67 \\
\hline Endoscopic polypectomy & 04 & 6.67 & 06 & 10 \\
\hline Frontal recess clearance & & & & \\
\hline
\end{tabular}

anterior ethmoidectomy and 16(26.7\%) went bilateral anterior ethmoidectomy. Posterior ethmoidectomy and sphenoidectomy was carried out in 13 patients of which $01(1.67 \%)$ under wentunilaterally while 12 (20\%) cases underwent bilaterally. Inferior turbinate submucosal diathermy was doen in 07 patients of whch $4(6.67 \%)$ underwent unilaterally and 3(5\%) underwent bi laterally.

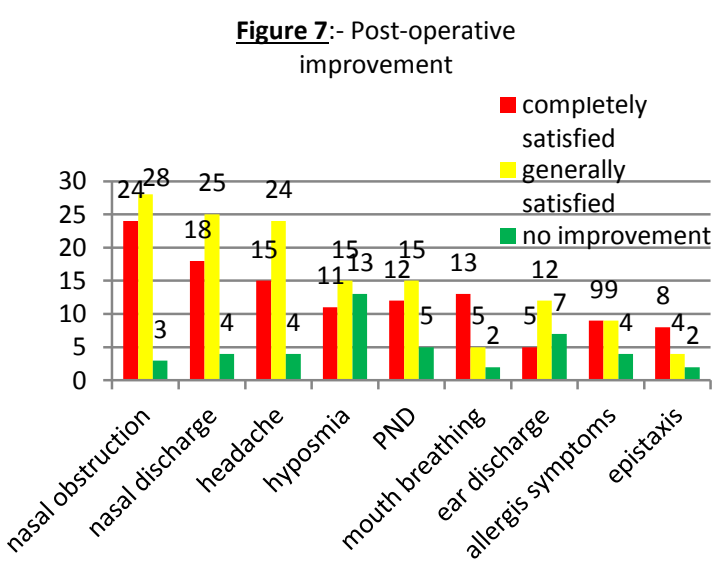

Endoscopic polypectomy was done in total of 15 patients out of which $8(13.33 \%)$ underwent unilaterally and $7(11.67 \%)$ underwent bilaterally. Frontal recess clearence was done in 10 patients out of which $4(6.67 \%)$ were done unilaterally and $6(10 \%)$ were done bilaterally.

After performing MIST, subjective improvement was assessed post-operatively (figure $7 \&$ table 4 ). Patients were divided into three categories on the basis of post-operative subjective improvement. Patients completely satisfied (CS) after sugery, generally satisfied (GS) after surgery and no improvement (NI) after surgery. Patients whichwere completely satisfied after surgery with the results(CS)- $39.51 \%$. Patients generally 
satisfied with the results after surgery(GS) were 46.04\%. And patients who did not improve after surgery were(NI)- $15.1 \%$. So combining CS and GS the overall success rate came to be $85.5 \%$. No major post-operative complication occurred in this study (table 5). 3(5\%) cases presented with postoperative echymosis and $2(3.33 \%)$ cases presented with subconjuctival haemorrhage. In the less severe group of complications, 6(10\%) patients presented with postoprerative adhesions. Subconjuctival haemorrage was seen in $2(3.33 \%)$ patients and post operative haemorrage was also seen in $2(3.33 \%)$ of cases.

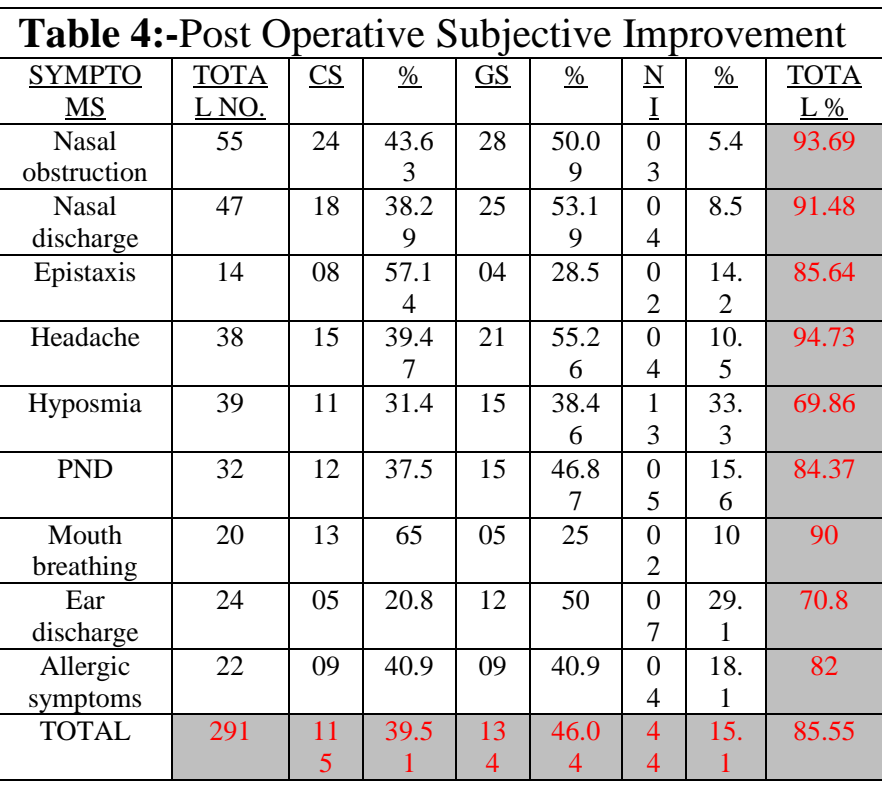

\begin{tabular}{|c|c|c|}
\hline \multicolumn{3}{|c|}{$\begin{array}{l}\text { Table 5:-Complications Encountered } \\
\text { During Surgical Procedures }\end{array}$} \\
\hline COMPLICATIONS & $\frac{\text { TOTAL }}{\text { NO. }}$ & $\underline{\%}$ \\
\hline Post op haemorrhage & $\overline{02}$ & 3.33 \\
\hline Csf leak & - & - \\
\hline Optic injury & - & - \\
\hline Orbital haematoma & - & - \\
\hline Echymosis & 03 & 05 \\
\hline Subconjuctival haemorhage & 02 & 3.33 \\
\hline $\begin{array}{c}\text { Restricted eyeball } \\
\text { movement }\end{array}$ & - & - \\
\hline Septal perforation & 04 & 6.67 \\
\hline $\begin{array}{l}\text { Orbital subcutaneous } \\
\text { emphysema }\end{array}$ & - & - \\
\hline Direct brain injury & - & - \\
\hline Nasolacrimal duct injury & - & - \\
\hline
\end{tabular}

Table 6:- Comparision Of Various Anatomical Variants In Ct Scan With Other Studies

\begin{tabular}{|c|c|c|c|c|c|c|c|}
\hline $\begin{array}{c}\text { Anatom } \\
\text { ical } \\
\text { Variant }\end{array}$ & $\begin{array}{c}\text { Zineric } \\
\mathrm{h} \\
\%\end{array}$ & $\begin{array}{c}\text { Bolg } \\
\mathrm{er} \%\end{array}$ & $\begin{array}{c}\text { Lloy } \\
\mathrm{d} \%\end{array}$ & $\begin{array}{c}\text { Calhoo } \\
\mathrm{n} \%\end{array}$ & $\begin{array}{c}\text { Kosli } \\
\mathrm{ng} \%\end{array}$ & $\begin{array}{c}\text { Ela } \\
\text { hi } \\
\%\end{array}$ & $\begin{array}{c}\text { Our } \\
\text { study }\end{array}$ \\
\hline $\begin{array}{c}\text { Paradox } \\
\text { ic MT }\end{array}$ & NA & 27.1 & 13.3 & 12 & 13.3 & 19 & 10.6 \\
\hline $\begin{array}{c}\text { Concha } \\
\text { Bullosa }\end{array}$ & 34 & 53.6 & 24 & 29 & 23.6 & 23 & 40.6 \\
\hline $\begin{array}{c}\text { Septal } \\
\text { deviatio } \\
\mathrm{n}\end{array}$ & 28 & $\mathrm{NA}$ & $\mathrm{NA}$ & 40 & $\mathrm{NA}$ & 51 & 90 \\
\hline $\begin{array}{c}\text { Agger } \\
\text { Nasi } \\
\text { Cells }\end{array}$ & $\mathrm{NA}$ & 98.5 & 03 & NA & 23.6 & 34 & 82.9 \\
\hline $\begin{array}{c}\text { Haller's } \\
\text { Cells }\end{array}$ & 10 & 45.9 & 15 & NA & 23.6 & 20 & 12.7 \\
\hline
\end{tabular}

Table 7:- Comparision of Varoius Mucosal Sinus Abnormalities During CT Scan Study With Other Studies

\begin{tabular}{|c|c|c|c|c|c|}
\hline Study & Maxillary & $\begin{array}{c}\text { Anterior } \\
\text { ethmoid }\end{array}$ & $\begin{array}{c}\text { Posterior } \\
\text { ethmoid }\end{array}$ & Sphenoid & Frontal \\
\hline $\begin{array}{c}\text { Diament } \\
\text { et al }\end{array}$ & 28.8 & 31.3 & NA & 7 & 0 \\
\hline $\begin{array}{c}\text { Kennedy } \\
\text { \&Zinerich }\end{array}$ & 66 & 78 & 31 & 16 & 34 \\
\hline $\begin{array}{c}\text { Hanas et } \\
\text { al }\end{array}$ & 24.4 & 28.4 & NA & 11 & 4.8 \\
\hline $\begin{array}{c}\text { Glater et } \\
\text { al }\end{array}$ & 70 & 48 & NA & NA & NA \\
\hline $\begin{array}{c}\text { Calhoun } \\
\text { et al }\end{array}$ & 93 & 34 & NA & 19 & 13 \\
\hline Our study & 54.25 & 60.6 & 22.4 & 14.89 & 22.4 \\
\hline
\end{tabular}

\section{Discussion}

Functional endoscopic sinus surgery in past used to involve wide, radical extirpation of sinus wall and content. The current modern endoscopic approach in nasal and sinus surgery i.e. Minimally Invasive Sinus Technique (MIST) is based on exact identification of focal disturbances, refined surgical intervention and functional restoration of aeration \& drainage by mucocilliary clearance. Minimally invasive sinus technique (MIST) is targeted endoscopic intervention introduced by Reuben C. Setliff in 1994, with goals originally identical to those reported for FESS, however there are distinct differences $^{2}$. In other words it can be said that 
MIST is a systematic reproducible approach to FESS with novice modifications aimed at restoring the normal mucosal anatomy \&physiology. In thisstudy the clinical profile of patients with chronic rhinosinusitis was evaluated. We have also attempted to quantify subjective levels of improvement both overall and with regard to specific symptoms MIST and meticulous post-operative care.

Levin HL in his series of 250 patients he reported nasal obstruction in $31.6 \%$, headache in $35.4 \%$ and discharge in $51.2 \%$ of patients ${ }^{3}$. In our study we have found that the nasal obstruction is most frequent symptom as it was present in $91.66 \%$ of patients followed by nasal discharge $78.3 \%$, hyposmia $65 \%$, headache $63.5 \%$ and PND $53 \%$. The reason may be the large group in his study, variations in history taking with climatic variations and individually varying symptomatology.

Benninger et al found $56 \%$ of patients undergoing FESS to be skin test positive whereas Rice et al reported a 15\% prevalence of allergy in patients in patients undergoing FESS. A large number of patients presented with the allergic symptoms in this study also. It constitutes $36.6 \%$ i.e. 22 patients. It is showing the increasing trends of allergic problems now days due to environmental pollution and occupational exposures. It is consistent with the overall prevalence rate of allergy in patients of chronic rhinosinusitis.

S.K. Kaluskar noted concha bullosa in $13 \%$ of cases $^{8}$, Zinerich and Kennedy et al encountered concha bullosa in $54 \%$ of cases on CT scanning 9 . In our study it was found that concha bullosa was present in $19(40.4 \%)$ cases out of which $11(23.4 \%)$ were bilateral and $8(17.02 \%)$ were unilateral (TABLE 6).

We compared various mucosal sinus abnormalities during CT scan with other studies. Our study was consistent with other studies which also showed almost same frequency of involvement of different sinuses (TABLE 7).
Catalono PJ, Roffmen E et al published a formal outcome study comparing MIST with FESS ${ }^{5,6,7}$. In this study the outcome from the MIST was surpassed those compared with FESS. More patients after MIST were improved to a level that was better than the normative symptoms data for the healthy individual \& general population. Study also demonstrated the surgical revision rate following MIST was $5.9 \%$ compared with anaverage of $0 \%$ following FESS. Steliff RC et al intheir study used geriatric population undergoing MIST for chronic rhinosinusitis, $84 \%$ patients feeling significantly better, $10 \%$ somewhat better and $6 \%$ unchanged. In this present study subjective improvement in patients undergoing MIST after asking improvement in symptomatologyin post-operative follow-up period was done. Patients completely satisfied with the results of surgery were $39.51 \%$, partially satisfied were $46.04 \%$ and patients with no improvement were $15.1 \%$.

Frakeinlicz suggested that the complications rate decreases with increasing experience. He reported complication rate of $29 \%$ in his first 90 cases he performed, compared with only $2.2 \%$ in next 90 . Stammberger and Wolf reported only two cases of CSF rhinorrhea ${ }^{1}$. Levine reported that $8.3 \%$ patients developed minor complications whereas only $0.7 \%$ developed major complications. In our study we had $2(3.3 \%)$ cases of postoperative hemorrhage as major complications. No incidence of CSF leak, optic injury or orbital haematoma was noted. $3(5 \%)$ patients developed ecchymosis and $2(3.3 \%)$ patients had subconjunctival hemorrhage postoperatively. Septal perforation was noted in 1(1.67\%) cases. On subsequent follow-up and nasal examination, 6(10\%) patients found to develop synechea followed by acute headache \& facial pan in $4(6.67 \%)$ patients. No incidence of subcutaneous emphysema, direct brain injury or nasolacrimal duct injury was there. 
Tables Showing Comparision Result Of Other Studies With Ours

\begin{tabular}{|c|c|c|}
\hline \multicolumn{3}{|c|}{ Kennedy et al } \\
\hline $\begin{array}{c}\text { Symptoms } \\
\text { improvement }\end{array}$ & After 1.5 yrs & After 7.8yrs \\
\hline Over all & 68 & 71 \\
\hline Headache & 64 & 68 \\
\hline Nasal discharge & 56 & 60 \\
\hline Nasal congetion & 66 & 65 \\
\hline Sense of smell & 53 & 52 \\
\hline Recurrent & 45 & 60 \\
infection & & \\
\hline
\end{tabular}

\begin{tabular}{|c|c|c|c|}
\hline \multicolumn{2}{|c|}{ Steven D. Schaefer et al } & & \\
\hline Symptoms & No. & \multicolumn{2}{|c|}{ Dele H. Rice et al } \\
\hline Improved & 83 & Symptoms & No. \\
\hline \multirow{2}{*}{$\begin{array}{l}\text { Improved with } \\
\text { one episode of } \\
\text { sinusitis }\end{array}$} & \multirow[t]{2}{*}{10} & Asymptomatic & 83 \\
\hline & & $\begin{array}{c}\text { Moderate } \\
\text { improvement }\end{array}$ & 10 \\
\hline $\begin{array}{l}\text { Little or no } \\
\text { improvement }\end{array}$ & 7 & $\begin{array}{c}\text { Operation } \\
\text { unsuccessful }\end{array}$ & 7 \\
\hline
\end{tabular}

\begin{tabular}{|c|c|}
\hline \multicolumn{2}{|c|}{ Yehudah Roth et al } \\
\hline Symptoms & No. \\
\hline Good excellent & 53 \\
\hline $\begin{array}{c}\text { Moderate } \\
\text { improvement }\end{array}$ & 26 \\
\hline No change & 21 \\
\hline Worse & 0 \\
\hline
\end{tabular}

\begin{tabular}{|c|c|}
\hline \multicolumn{2}{|c|}{ Yamagishi et al } \\
\hline Symptoms & No. \\
\hline $\begin{array}{c}\text { Subjective } \\
\text { improvement }\end{array}$ & 70 \\
\hline Objective \\
improvement
\end{tabular}

\section{Conclusion}

Chronic Rhino-sinusitis usually affects age group ranging from 10-30 yrs with common mode of presentation being nasal obstruction, nasal discharge, headache, and postnasal discharge.

Pre-operative nasal endoscopy helps in diagnosis of sinonasal pathology by revealing structural details and anatomical variations in nasal cavity to a greater extent there-by gives a clear cut idea of extent of disease prior to surgical intervention. Nasal endoscopy confirms the findings of anterior rhino-scopy.

CT scan accurately defines micro-anatomical locales in and around the osteomeatal unit, and also identifies dangerous anatomical variants like dehiscent optic nerve canal and carotid canal. It gives the exact extent of sinus disease and acts as anatomical road map prior to surgery.

CT scan is foundation on which surgery should be based. Surgical steps should be pre-planned in relation to CT scan done during least symptomatic period. If the disease encountered during surgery is more extensive than anticipated, do not alter preplanned surgical decision.

Avoid manipulating or interfering with the osteomeatal unit if disease is not evident on CT scan.

Removal of entire uncinate process and anterior ethmoid is too aggressive a procedure for treating limited disease in the osteomeatal area. It can result in the loss of normal nasal mucosa, excessive scarring and iatrogenic frontal recess obstruction. Unnecessary stripping of mucosa leads toscarring which in turn causes of loss of cilliary lining increases the risk of recurrent infections. This can worsen the symptom and patient can become "sinus cripple". Because MIST does not manipulate the primary maxillary sinus ostium, the latter remains in oblique or horizontal plane, making it less likely to be obscured by lateralized middle turbinate.

Our study shows that MIST is a safe and effective method of treatment in cases of Chronic Rhino-sinusitis in all age group of patients.

MIST clearly offers a number of advantages.

We can conclude by saying MIST provides a better understanding of sinus pathophysiology and opens the new horizons of treating them with minimal injury to the surrounding normal mucosa.

\section{References}

1. Stammberger H, Wolf G; Headaches and sinus disease: the endoscopic approach. The Annals of Otology, Rhinology \& Laryngology. Supplement [1988, 134:323].

2. Setliff RC, Parsons DS; the hummer new instrumentation for functional endoscopic sinus surgery. American Journal of Rhinology, Volume 8, Number 6, November-December 1994, pp. 275278(4). 
3. Levine HL; functional endoscopic sinus surgery : evaluation surgery and follow-up of 250 patients. Laryngosope 100, 7981(1990).

4. Catalano PJ, Roffman EJ; Evaluation of role of middle meatal stenting after the minimally invasive technique (MIST). Otolaryngol head neck surg 2003; 128(6); 875-81.

5. Catalano PJ, Setliff RC, Catalano LA Minimally invasive sinus surgery in the geriatric patient. OperTechn Otolaryngol Head Neck Surg 2001;12:85-90.

6. Catalano PJ, Roffman EJ Long-term outcome in patients with chronic sinusitis following the minimally invasive sinus technique (MIST). Presented at the American Rhinologic Society Fall Meeting, Denver, CO, September 8, 2001.

7. Catalano PJ, Roffman EJ The minimally invasive sinus technique (MIST): clinical outcome in 55 cases. Presented at the Triological Society Southern Section Meeting, Captiva Island, FL, January 11, 2002.

8. Kaluskar SK, Patil NP, Sharkey AN. The role of $\mathrm{CT}$ in functional endoscopic sinus surgery. Rhinology [1993, 31(2):49-52].

9. Zinreich JS et al. Paranasal sinuses: CT imaging requirements for endoscopic surgery.June 1987 Volume 163, Issue 3.

10. Steven DS, Schaefer MD, Lanny G. endoscopic management of frontal sinus disease: laryngoscope 100: February 1990. Pg 155-160. 